\section{No evidence of association between complement factor I genetic variant rs10033900 and age-related macular degeneration}

European Journal of Human Genetics (2012) 20, 1-2; doi:10.1038/ejhg.2011.118; published online 12 October 2011

In 2008, an association between age-related macular degeneration (AMD) and single nucleotide polymorphisms (SNPs) on chromosome $4 \mathrm{q} 25$ was reported in this journal by Fagerness et al ${ }^{1}$ studying a large

Table 1 Demographic characteristics of the English and the Scottish subjects

\begin{tabular}{cccc}
\hline \multicolumn{2}{c}{ English subjects } & \multicolumn{2}{c}{ Scottish subjects } \\
Cases & Controls & Cases & Controls \\
$(\mathrm{N}=859)$ & $(\mathrm{N}=423)$ & $(\mathrm{N}=505)$ & $(\mathrm{N}=351)$ \\
\hline
\end{tabular}

\begin{tabular}{lcc}
\hline Disease status, N & & \\
ARM & 29 & 261 \\
GA & 142 & 55 \\
CNV & 688 & 189
\end{tabular}

Sex, $N(\%)$
Female $\quad 472(55.0) \quad 253(59.8) \quad 316(62.6) \quad 199(56.7)$

Mean age, year $( \pm S D)$

$78.9( \pm 7.2) \quad 75.0( \pm 7.8) \quad 77.8( \pm 9.2) \quad 78.0( \pm 8.5)$

Abbreviations: ARM, age-related maculopathy; CNV, choroidal neovascularisation; GA, geographic atrophy.
US-based sample of around 1200 cases with advanced AMD and 800 controls. The association signal extended over a region of about $175 \mathrm{~kb}$, the most associated variant $\left(P<10^{-7}\right)$ being the SNP rs10033900 near the complement factor I (CFI) gene. Two replication studies $^{2,3}$ published also in this journal provided some additional support for an AMD susceptibility locus in this region. In the course of candidate gene studies of AMD, we had previously investigated SNPs spanning CFI including rs 10033900 in a UK case-control sample, which shows the expected associations with the wellestablished AMD-susceptibility loci CFH, ARMS2, CFB and C3. No evidence of association with the CFI variants was observed. Following publication of the reports cited above we have typed rs10033900 in additional cases and controls in two independent samples from England and Scotland to investigate this further.

Full details of the phenotyping criteria have been reported previously. ${ }^{4}$ The English sample comprised of 859 cases with predominantly advanced AMD, either geographic atrophy (GA) or choroidal neovascularisation (CNV) and 423 examined controls. The Scottish sample consisted of 505 cases with either intermediate disease (age-related maculopathy, ARM) or advanced AMD, and 351 examined controls. Summary demographics of the two cohorts are detailed in Table 1. The English and Scottish samples were genotyped in separate laboratories using different methodologies (ABI Prism SNaPshot Multiplex Kit and Taqman SNP Genotyping Assay respectively, both from Applied Biosystems, Foster City, CA, USA). No departure from Hardy-Weinberg equilibrium was observed either in the English $(P=0.92)$ or in the Scottish $(P=0.32)$ controls, and allele frequencies were almost identical (C allele, $50.1 \%$ and $49.6 \%$, respectively). A genetic additive model was assessed using the CochranArmitage trend test and corresponding $P$-values are reported. ORs were calculated using referent $\mathrm{C}$ allele as per Fagerness et $\mathrm{al}^{1}$ and are presented with 95\% CIs. A pooled OR with corresponding 95\% CI and $P$-value was estimated using both English and Scottish samples using the Mantel-Haenszel (fixed-effects) method of meta-analysis. Heterogeneity between the two studies was assessed using the quantity $I^{2}$ and $\chi^{2}$-test.

Table 2 presents results from an association analysis between rs10033900 and advanced AMD in the English and Scottish samples together with a meta-analysis. The OR estimates showed no evidence of association in either cohort (English: $\mathrm{OR}=0.94,95 \% \mathrm{CI}=0.80-1.12$; Scottish: $\mathrm{OR}=0.96,95 \% \mathrm{CI}=0.76-1.23)$. No heterogeneity between the two cohorts was observed. The Mantel-Haenszel summary OR ( $0.95,95 \% \mathrm{CI}=0.83-1.09, P=0.47)$ confirmed the lack of evidence of an association at SNP rs10033900 in these two independent samples.

Table 2 Association analysis for SNP rs 10033900 comparing cases of advanced AMD (GA or CNV) with controls in the English and the Scottish samples

\begin{tabular}{|c|c|c|c|c|c|c|c|}
\hline & \multicolumn{2}{|c|}{$\begin{array}{l}\text { Referent allele } \\
\text { C frequency }\end{array}$} & \multicolumn{2}{|c|}{$\begin{array}{c}\text { Genotype counts } \\
\text { (TT/TC/CC) }\end{array}$} & \multirow[b]{2}{*}{$O R$} & \multirow[b]{2}{*}{$95 \% \mathrm{Cl}$} & \multirow[b]{2}{*}{$\mathrm{P}$-value ${ }^{\mathrm{b}}$} \\
\hline & Cases & Controls & Cases & Controls & & & \\
\hline English subjects & 0.48 & 0.50 & $211 / 407 / 186$ & 102/207/101 & 0.94 & $0.80-1.12$ & 0.50 \\
\hline Scottish subjects & 0.50 & 0.50 & $47 / 130 / 45$ & 77/177/80 & 0.96 & $0.76-1.23$ & 0.76 \\
\hline Meta-analysis & & & & & 0.95 & 0.83-1.09 & 0.47 \\
\hline
\end{tabular}

Abbreviations: AMD, age-related macular degeneration; Cl, confidence interval; CNV, choroidal neovascularisation; GA, geographic atrophy; OR, odds ratio.

aReferent allele $C$ as per Fagerness et al. ${ }^{1}$

${ }^{b}$ Cochran-Armitage trend test for the English and the Scottish subjects; $\chi^{2}$-test for the meta-analysis (Heterogeneity: $P^{2}=0 \% ; \chi^{2}=0.02, P=0.89$ ) 
Adjusting the analysis for age or confining the analysis to cases with either $\mathrm{CNV}$ or GA, or including cases with intermediate disease (ARM), did not significantly alter the estimates (results not shown).

Given the strong association signal reported by Fagerness et al ${ }^{1}$ and the fact that our study is comparably powered, it is surprising we could not replicate this finding. The study by Ennis et a ${ }^{2}$ is the only previous report based on a UK sample and failed to find significant evidence of association with $\operatorname{rs} 10033900(P=0.135)$. Kondo et $a l^{3}$ obtained weak evidence of an association with rs10033900 $(P=0.036)$ in their Japanese sample and argued in favour of a recessive mode of inheritance $(P=0.0035)$. Testing a recessive genetic model did not show significance in either of our UK samples (English sample: $P=0.56$; Scottish sample: $P=0.60)$.

Recently, Neale et al ${ }^{5}$ reported a genome-wide association study (GWAS) of advanced AMD using largely the same sample as Fagerness et $a^{1}$ but with additional controls. As in the earlier study, they found association with rs7690921 $\left(P<10^{-3}\right)$ in the CCDC109B gene $80 \mathrm{~kb}$ from rs10033900 $\left(r^{2}=0.40\right)$. Replication samples were studied and meta-analysis gave a stronger signal of association $\left(P<10^{-8}\right)$. Chen et $a^{6}$ carried out another genome-wide investigation on a sample of around 2000 cases and 1000 controls, which confirmed previous evidence from Fagerness et $\mathrm{al}^{1}$ of an association with rs2285714 $\left(P<10^{-6}\right)$ in the PLA2G12 gene $20 \mathrm{~kb}$ from $\operatorname{rs} 10033900\left(r^{2}=0.70\right)$. As the genotyping platforms used in these two GWASs did not include rs10033900, no conditional analysis was possible and the signals in CCDC109B and PLA2G12 were interpreted as a proxy for rs 10033900. More recently, the GWAS by Kopplin et al ${ }^{7}$ did not report evidence of association (cut-off $\mathrm{P}<10^{-4}$ ) for the CFI locus in two discovery samples.

McCarthy et $a l^{8}$ have enumerated the possible explanations for failure to replicate a reported association as either the original finding being a false positive or the presence of some source of heterogeneity to which the difference in findings can be attributed, such as variable patterns of linkage disequilibrium between the genotyped SNP and untyped causal alleles, differences in the distribution, frequency or effect size of the causal alleles or the impact of non-additive interactions with other genetic variants or environmental exposures. For AMD, there have been several seemingly convincing reports of associations, which have not been replicated by subsequent studies, for example with SERPING $1^{9-11}$ and TLR3. ${ }^{12-14}$

On the available evidence it seems likely that variants at $4 \mathrm{q} 25$ do influence susceptibility to AMD. However, the variability observed in the results discussed above together with our complete lack of association for the index variant rs10033900 in two well-characterised independent UK samples leaves uncertainty as to which SNPs/genes are most strongly associated across different populations. Additional studies and a metaanalysis of the data are needed to clarify the nature of the association between AMD and variants in the extended CFI region.

\section{CONFLICT OF INTEREST}

The authors declare no conflict of interest.

\section{ACKNOWLEDGEMENTS}

This work has received funding from the Medical Research Council, United Kingdom (JRWY, ATM, DGC), the Macular Disease Society (JRWY, ATM), Guide Dogs for the Blind Association (ATM, JRWY, DGC, CB), the Wellcome
Trust (DGC), the Juvenile Diabetes Research Foundation (DGC), the Macula Vision Research Foundation (AFW), the Chief Scientist Office, Scotland (AFW, BD, CH), the Department of Health's NIHR Manchester Biomedical Research Centre (PB) and the NIHR Biomedical Research Centre for Ophthalmology at Moorfields Eye Hospital and UCL Institute of Ophthalmology (JRWY). The views expressed in the publication are those of the authors and not necessarily those of the Department of Health.

Valentina Cipriani ${ }^{1,2}$, Baljinder K Matharu ${ }^{3}$, Jane C Khan ${ }^{3}$, Humma Shahid ${ }^{3}$, Caroline Hayward ${ }^{4}$, Alan F Wright ${ }^{4}$, Ana Maria Armbrecht ${ }^{5}$, Baljean Dhillon ${ }^{5}$, Simon P Harding ${ }^{6}$, Paul N Bishop ${ }^{7,8}$, Catey Bunce ${ }^{2}$, David G Clayton ${ }^{3}$, Anthony T Moore ${ }^{1,2}$ and John RW Yates ${ }^{1,2,3}$ ${ }^{1}$ Department of Genetics, Institute of Ophthalmology, University College, London, UK; ${ }^{2}$ Moorfields Eye Hospital, London, UK; ${ }^{3}$ Department of Medical Genetics, Cambridge Institute for Medical Research, University of Cambridge, UK; ${ }^{4}$ Medical Research Council Human Genetics Unit, Institute of Genetics and Molecular Medicine, Edinburgh, UK;

${ }^{5}$ Princess Alexandra Eye Pavilion, Edinburgh, UK; ${ }^{6}$ Ophthalmology Research Unit, School of Clinical Sciences, University of Liverpool, Liverpool, UK;

${ }^{7}$ School of Biomedicine, Faculty of Medical and Human Sciences, University of Manchester, Manchester, UK;

${ }^{8}$ Manchester Academic Health Science Centre, Central Manchester Foundation Trust, Manchester, UK E-mail:v.cipriani@ucl.ac.uk

1 Fagerness JA, Maller JB, Neale BM, Reynolds RC, Daly MJ, Seddon JM: Variation near complement factor I is associated with risk of advanced AMD. Eur J Hum Genet 2009; 17: 100-104.

2 Ennis S, Gibson J, Cree AJ, Collins A, Lotery AJ: Support for the involvement of complement factor I in age-related macular degeneration. Eur J Hum Genet 2010; 18: 15-16.

3 Kondo N, Bessho H, Honda S, Negi A: Additional evidence to support the role of a common variant near the complement factor I gene in susceptibility to age-related macular degeneration. Eur J Hum Genet 2010; 18: 634-635.

4 Yates JRW, Sepp T, Matharu BK et al: Complement C3 variant and the risk of age-related macular degeneration. N Engl J Med 2007; 357: 553-561.

5 Neale BM, Fagerness J, Reynolds R et al: Genome-wide association study of advanced age-related macular degeneration identifies a role of the hepatic lipase gene (LIPC). Proc Natl Acad Sci USA 2010; 107: 7395-7400.

6 Chen W, Stambolian D, Edwards AO et al: Genetic variants near TIMP3 and high-density lipoprotein-associated loci influence susceptibility to age-related macular degeneration. Proc Natl Acad Sci USA 2010; 107: 7401-7406.

7 Kopplin LK, Igo RP, Wang Y et al: Genome-wide association identifies SKIV2L and MYRIP as protective factors for age-related macular degeneration. Genes Immun 2010; 11: 609-621.

8 McCarthy MI, Abecasis GR, Cardon LR et al: Genome-wide association studies for complex traits: consensus, uncertainty and challenges. Nat Rev Genet 2008; 9: 356-369.

9 Ennis S, Jomary C, Mullins R et al: Association between the SERPING1 gene and age-related macular degeneration: a two-stage case-control study. Lancet 2008; 372 : $1828-1834$.

10 Allikmets R, Dean M, Hageman GS et al: International AMD Genetics Consortium. The SERPING1 gene and age-related macular degeneration. Lancet 2009; 374: 875-876.

11 Park $\mathrm{KH}$, Ryu E, Tosakulwong $\mathrm{N}$, Wu Y, Edwards AO: Common variation in the SERPING1 gene is not associated with age-related macular degeneration in two independent groups of subjects. Mol Vis 2009; 15: 200-207.

12 Yang Z, Stratton C, Francis PJ et al: Toll-like receptor 3 and geographic atrophy in age-related macular degeneration. N Engl J Med 2008; 359: 1456-1463.

13 Allikmets R, Bergen AA, Dean M et al: International Age-related Macular Degeneration Genetics Consortium. Geographic atrophy in age-related macular degeneration and TLR3. N Engl J Med 2009; 360: 2252-2254.

14 Edwards AO, Swaroop A, Seddon JM: Geographic atrophy in age-related macular degeneration and TLR3. N Engl J Med 2009; 360: 2254-2255. 